Few-Body Systems 40, 129 (2006)

DOI 10.1007/s00601-006-0168-9

Printed in The Netherlands

\title{
Erratum
}

\section{Dynamical Hierarchy in Transition States of Reactions}

\author{
C. B. $\mathrm{Li}^{1}$, A. Shojiguchi ${ }^{2}$, M. Toda ${ }^{2}$, and T. Komatsuzaki ${ }^{1,3, *}$
}

1 Nonlinear Science Laboratory, Department of Earth and Planetary Sciences, Faculty of Science, Kobe University, JST/CREST, Nada, Kobe 657-8501, Japan

2 Department of Physics, Faculty of Science, Nara Women's University, Nara 630-8506, Japan

3 Department of Theoretical Studies, Institute for Molecular Science, Myodaiji, Okazaki 444-8585, Japan

[Few-Body Systems 38, 173 (2006)]

Received August 23, 2006; accepted August 25, 2006

Published online November 22, 2006; (C) Springer-Verlag 2006

Equation (5) in the article should read

$$
\begin{aligned}
H= & \frac{p_{1}^{2}+p_{2}^{2}+p_{3}^{2}}{2}+a_{1} q_{1}^{2}+a_{2} q_{1}^{4}+\frac{\omega_{2}^{2} q_{2}^{2}+\omega_{3}^{2} q_{3}^{2}}{2} \\
& +\sum_{i=0}^{2} \exp \left[-\alpha_{i}\left(q_{1}-q_{1 i}\right)^{2}\right]\left[\beta_{i} q_{2}^{2} q_{3}^{2}+\gamma_{i} q_{1}^{2}\left(q_{2}^{2}+q_{3}^{2}\right)\right],
\end{aligned}
$$

where we corrected the misprints of the subscripts in the fourth term.

\footnotetext{
* E-mail address: tamiki@kobe-u.ac.jp
}

\footnotetext{
Verleger: Springer-Verlag GmbH, Sachsenplatz 4-6, 1201 Wien, Austria. - Herausgeber: Prof. Dr. B. L. G. Bakker, Theoretical Physics Group, Department of Physics and Astronomy, Vrije Universiteit, De Boelelaan 1081, 1081 HV Amsterdam, The Netherlands. - Redaktion: De Boelelaan 1081, 1081 HV Amsterdam, The Netherlands. - Satz und Umbruch: Thomson Press (India) Ltd., Chennai. - Offsetdruck: Krips bv, Kaapweg 6, 7944 HV Meppel, The Netherlands. - Verlagsort: Wien. - Herstellungsort: Meppel. - Printed in The Netherlands.
} 